\title{
How are women fostering home Internet adoption? A study of home-based female Internet users in Bangladesh
}

\author{
Naziat Choudhury \\ Lecturer \\ Department of Mass Communication and Journalism \\ University of Rajshahi \\ Rajshahi \\ Bangladesh \\ Email: naziat96@yahoo.com
}

\begin{abstract}
This study proposes to investigate what role women are playing in bringing the Internet to the home in Bangladesh. Home-based female Internet users are focused upon herein. This study is based on the appropriation phase of the domestication of technology theory and the model of becoming an Internet user. Semi-structured interviews are conducted among sixteen participants. The central theme of this study is to understand how women participate in the decision-making process associated with Internet adoption. The Internet is brought home for many interesting reasons. Through the Internet some women are making an effort to voice their concerns and thus bring changes to their own and their families' lives. Thus this study offers an in-depth look at home-based women Internet users in Bangladesh.
\end{abstract}

Keywords: Women, Internet, Communication, Domestication, Decision-making

\section{Introduction}

B angladesh is a South Asian country where a patrilineal and patriarchal social system persists even today. Discrimination against women is a common phenomenon in the country. Stories of suppression of women are visible in every sector. Realizing the need to bring changes in their lives, women are gradually taking steps towards achieving that end. More and more women are entering the professional world, even those professions that are widely known as men's, such as engineering and medicine.

Along with other factors, new technologies are said to be assisting women in uplifting their position in society. One such technology is the Internet. Studies done in developing countries have shown the significance of this technology in the lives of women. These studies have also presented women's Internet use pattern and proposed reasons why there are fewer women online. But I believe that along with observing women's online activities as such, emphasis should also be on the decision-making process related to the Internet. How women are bringing this technology home and what role they are playing in using it need to be studied. Thus I have decided to focus at the micro level and study what role women are actually playing in this regard. At this point, I must add that I did not come across any such studies in Bangladesh. I hope this study will provide an in-depth and broader understanding of the matter in that country and to some extent in other developing countries as well.

Women have been seen traditionally as users rather than as designers, developers or innovators of technology. The reference here 
is to users of less complex technologies such as domestic technologies (Cockburn, Cockburn \& Ormrod, cited by Youngs, 2005). Researches on gender and technology have evolved through several phases as Wajcman (2000) has pointed out. Three broad themes are visible in this area of studies. The inception of gender and technology studies highlighted the area of consumption, where the focus was on how "the sexual division of labour separated women from control over the technologies they used, both at the workplace and at home" (Wajcman, 2000, p. 449). Then the focus shifted towards "the social relations of technical design and innovations" (Wajcman, 2000, p. 460). At present, gender and technology studies are concentrating on "cyberfeminism that embraces new technology as a source of empowerment for women" (Wajcman, 2000, p. 460). Feminists have emphasized the ability of the new technologies to provide a space for women where they can breathe without facing the burden of social discriminations. Lawley (1993) once said:

"By providing women with an opportunity to express their ideas in a way that transcends the biological body, this technology [the Internet] gives them the power to redefine themselves outside of the historical categories of 'women', 'other' or 'object' ".

Although some technologies may bear the potential to emancipate a user, there remains the lingering question about access to technologies. No matter what kind of technology it is, women seem to face the most hurdles in accessing and using it. This may not be true, however, in the case of domestic technology as it is made for women and intended to be used by women. Domestic technology thus seems to come with an assigned set of gender identity. Even the promotional materials for such technology depict this perspective as well.

With regard to technology as a whole, women are in a disadvantaged position as they "have less income, education, time, mobility and face religious or cultural constraints that restrict their access to and use of technology" (Odame, 2005, p. 15). Women's disengagement with technology and their role in the family is often described in the following terms:

"Seldom does anyone consider that women may take less interest in new technologies out of a sense of pragmatism, that is, out of their need to deal with a multitude of tasks, meet a variety of demands, and play diverse roles with limited time...they have a pressing need to attend to many diverse duties and have little time to experiment with new technologies simply out of a sense of interest" (Rathgeber, 2000, p.23).

Within that context I want to bring out the viewpoints of female Internet users in Bangladesh and how they handle the small environment of the home, where some women spend more time than anywhere else. How women domesticate the Internet or what role they play in bringing the Internet home have been studied mainly by western scholars (Bakardjieva, 2005). Unfortunately, scholars and researchers in developing countries have seldom paid attention to this topic. The debate by western scholars, however, about female home Internet usage is prominent in the literature about Internet usage in developing countries. It is often argued that due to the high expenses associated with Internet use, women generally tend to use it only at public places. On the other hand, some scholars note that the majority of women are not professionals and do not feel safe in using the Internet in public places such as a cyber café. Cabrera-Balleza (2006) explains:

"Internet cafes are located in places that women may not be comfortable frequenting or that are culturally inappropriate for them to visit. Frequently, communication facilities in developing countries are in offices or in public spaces that operate during office hours. Given the genderbased multiple roles and reproductive responsibilities assigned to them, women have little extra time and such public access centers may not be open when women are available to visit them. Some communication centers are open in the evening, but either because of cultural limitations or lack of general safety to go 
out at night, women opt not to go to them."

Taking this view into consideration, I have decided to focus on female home Internet users. Here I would like to quote Harcourt (2002) who has emphasized the importance of focusing on home-based female Internet users. Although her focus was more on the political power of women within the home, I believe it is pertinent to my work:

"The home is a crucial terrain of political struggle. Not only is it where many relations of power (within the family) are negotiated, it is also where much vital but undervalued labor is produced [...] The home and immediate community are where most women express themselves, and it is here, potentially, that the possibilities of the terminals in the home, the personal and political exchanges this potentially facilitates, could change women's political lives [...] Women are building a strong layer of support through the Web and Internet from moments of great need and social crisis, to safe spaces where personal struggles can be discussed and solutions shared. The medium has lent itself to women's ways of working; where the personal can truly be political. Where women can type and petition support from their homes at times that suit them, evading public censorship, finding the voice they cannot take recourse to outside their doors" (Harcourt, 2002, pp.153-154).

Statistical data about women accessing the Internet at home in Bangladesh do not exist. But, according to the ex-President of the Internet Service Providers (ISPs) of Bangladesh, twenty percent of Internet users in Bangladesh are women and this data is based on home-based Internet users (Choudhury, 2004).

Going online or getting connected to the Internet in Bangladesh is neither an easy nor an inexpensive matter for the majority of the population as scholars and statistics show. The cost of connecting to the Internet is equivalent to providing a year's supply of food for a family (Hafkin \& Taggart, 2001). In the United Nation's ICT Diffusion Index, Bangla- desh stands at position number 171, the lowest among South Asian countries (Global Information Society Watch, 2007, p. 110). Given these circumstances, I want to investigate how women are managing to access this medium as well as other issues related to access.

Bakardjieva (2005) emphasizes that the majority of research focusing on the sociocultural aspect of the Internet is conducted in the developed world where there "is a lingering tendency among both scholars and policymakers to assume that patterns of adoption, institutionalization and use emerging in these societies are paradigmatic and will be reproduced, sooner or later, in the rest of the world" (Bakardjieva, 2005, p. 4). Research done in the developing world has mainly focused on the obstacles of Internet use, where socioeconomic, cultural and political features are discussed to highlight the reasons for women's limited presence on the Internet. Despite these obstacles, however, some women are making an effort to log on. Here I will focus on these women and their choices and decisions related to accessing the Net in terms of the socio-economic, cultural, political and traditional contexts.

\section{Theoretical Framework}

I will discuss the experiences of women based on their situational context. I propose to do so through the lens of the appropriation phase of the "domestication of technology" theory (Silverstone et al., 1992). The domestication of technology theory facilitates the investigation of users' perspectives. Roger Silverstone, Eric Hirsch and David Morley introduced this theory in the early 1990s. Regarding the theory, Bakardjieva notes, "it is intended to capture the appropriation of new technologies and their adaptation to the spaces and rhythms of everyday settings, most typically the home" (Bakardjieva, 2005, p. 24). This theory has four phases or dimensions: appropriation, objectification, incorporation and conversion (Silverstone et al., 1992). "Appropriation" is the phase where users think about and decide upon buying a technology. "Objectification" is the phase where a technology is placed within the domain of the home. The use aspect of a technology is analyzed in 
the "incorporation" section. In the "conversion" stage a connection is established between the household and the public world by displaying a certain object or technology.

At the appropriation level, not everyone has a say in the decision making process related to the acceptance of a technology. The Feminist scholars Bakardjieva (2001) and Berg (1999) have argued that emphasis should be placed on "who decides which technology is being appropriated, rather than studying the family as a unit and ignoring the different positions of various family members" (cited by Hynes and Rommes, 2006, p. 128). Thus, at this level I tried to look at who decides what to buy, how that decision is made, and for whom they buy the technology. Since in Bangladesh technology is always seen as male area, I attempted to investigate whether this situation really exists.

Along with the appropriation phase, I have decided to use the "becoming an Internet user" model offered by Bakardjieva (2005). This model emphasizes the user's own situated motivation and the accessibility of the necessary items. Specifically, it is a process that

"takes place in everyday micro-settings and draws from public discourses, organizational practices, situated practical reasoning and the experience of fellowmen/women. It involves local interpretations of the technology and the discovery of its properties as they prove to afford new relations between the user and entities in his or her surrounding world. Strategically enacting or submitting to these new relations and action possibilities, users weave different practical definitions of the Internet. Along with that, different genres of use and user types emerge and proliferate" (Bakardjieva, 2005, p. 6).

I believe that the concept of the Grameen Phone supports Bakardjieva's model. The example of Grameen Phone in Bangladesh indicates how a technology, which was initially only thought of as a medium of communication, has now proven to be a medium of emancipation as well for women in rural areas. Grameen Phone is probably the best illustration of how a technology is at first de- signed by and for the developed world and later brought into the context of a developing country, where it takes on a different meaning and use. Keeping in mind that the Internet is a new technology in Bangladesh, it should be interesting to look into the process women go through in order to access this medium. In my study, I will use the "appropriation phase" of the domestication of technology-theory and the "becoming an Internet user"-model.

\section{Methodology}

In order to analyze the true voices of women, I have decided to conduct semistructured interviews. Women's perspectives are seldom heard in the technology related arena, so I believe it is important to analyze their perspective. Here Internet users are those women who use the Internet at home and do not belong to any technology related field, academically or professionally.

Snowball sampling through social networking was used to recruit subjects for this study. The lack of scope for finding subjects related to the research I am doing through any other way is why I chose snowball sampling. In my social network, I requested everyone to distribute my call for participation in my research. Those interested were requested to phone or email me. Sixteen respondents from two cities in Bangladesh were selected. One of the cities (Dhaka) is more developed than the other city (Rajshahi). A developed and a less developed city were selected to see if any differences among users could be found. In both cities two female respondents were selected from each of the following categories: small and large businesses, professions, students, and housewives.

Women from different professional and non-professional backgrounds were selected in order to hear their respective voices. Those who responded to my call first in each category were selected initially for interviewing. For example, the first two housewives who answered my call were selected, but only if they continued with the interview process to the end. If one decided not to continue with the interview process, then the next housewife in sequence was interviewed. Two women from each category were selected to make the results more representative. 
The responses were analyzed and interpreted based on the information given in the interviews. The objectives of the research were kept in mind while conducting the analysis. In view of the research problem proposed, I decided to analyze the data by following qualitative thematic analysis. The analysis is "based on the identification of themes" in the data (Seale, 2004, p. 509). The information being analyzed was derived from my notes and tape recordings. The interviews were transcribed and the themes were categorized broadly.

\section{Socio-economic background}

The line of inquiry is as follows. First the socio-economic background of those interviewed in this study is explored. The age of the Internet users in the less developed city, Rajshahi, ranges from 18 to 56 years. A similar age range is found in the more developed city, Dhaka. I argue that the presence of older women among Internet users is a positive sign given that statistics show that the majority of Internet users around the world are from the younger generation. Chen, Boase and Wellman (2002) have found that most of the Internet users in the world are over 30 (with a mean age of 37 years).

Based on the sample of my study, I am able to investigate the reasons and motivations that lead older women to connect to the Internet. In Bangladesh, traditionally girls are encouraged to learn more about issues related to home-making and family wellbeing and boys are encouraged to acquire technical knowledge. This viewpoint was even more prevalent at the time when the older women of my respondent group were growing up. Thus, it is encouraging to see that women from that generation are using new technologies. Though the number of Internet users from the older age group may not be statistically significant, I consider it important that one takes a glimpse at the practices of those we tend to ignore, assuming they are too old to use new technology. In the context of Bangladesh, the use of the Internet by an older generation of women provides a scope to investigate how women with no modern technical background at all are trying to partake in the advantages offered by the Internet.
The level of education is focused upon next. Data show that female Internet users in both cities are highly educated, whereas the country's female adult literacy rate is 40.8 percent. Statistics show that the net primary enrolment rate among girls is 96 percent and the gross secondary enrolment rate is 48 percent (UNDP's Human Development Report, 2007). This indicates a high dropout rate among girls. This comes as no surprise if we look at Bangladeshi society. As girls grow older, the outside world gradually shuts them out. As young children, they are allowed to play outside and mix with boys, but as soon as they start passing the age of seven or eight they are gradually confined within the arena of the home. They are not allowed to roam around alone. Parents cautiously observe all their moves. "At the core of the institution is the notion that the izzat (honor) of the family resides in the virtue of its women; constant surveillance is necessary to ensure that women do nothing to bring sharam (shame) on their kin" (Kabeer, 2005, p. 277). Despite social and cultural restrictions, women who realize the importance of education are making educational efforts, as the following statistics show. In the junior secondary and secondary schools, almost half the students are female. At the university level, out of 149,340 students 33,607 are women (BANBE cited in Basic Education Data and Indicators in Bangladesh, 2006). These women are also trying to take advantage of the new medium. Among the women in my respondent group the highest level of education achieved at the moment of the interview ranges from grade 11 to doctoral degree, with the majority having a master's degree.

Not only are they highly educated, but they also have a high monthly income as the data indicates. When business and professional women are asked about their monthly income, some decline to answer. The reason for reluctance to provide their income information is not very clear to me. Although it is assured at the commencement of the interview that their identity will not be revealed, they still decline to state their income. I must note here that I did not ask for the exact figure, but only for the range within which their income falls. Out of eight business and professional women in my study, only four offered their income in- 
formation. Based on their information it can be concluded that these respondents belong to the middle and upper middle classes of Bangladeshi society. In 2006-2007, the per capita annual income in Bangladesh was the equivalent of US $\$ 520$ (Statistical Pocket Book, 2007). In comparison to this, the incomes of my respondents in both cities are much higher. The majority earns at least the equivalent of US $\$ 250$ per month. Not only in Bangladesh, but also in other parts of the developing world, female Internet users belong to "a tiny elite of high income urban dwellers" (Hafkin \& Taggart, 2001 p.13). It has also been noted:

"In India all electronic media, ranging from satellite television to e-mail and the Internet, are accessible only to the privileged classes and cater almost exclusively to their predominantly male information and entertainment needs and desires. [...] In the Philippines [...] an Internet hookup amounting to US $\$ 200$ is beyond the reach of even the middle class [...] It is a luxury item for most families" (Bautista, cited by Hafkin \& Taggart, 2001, p.16.)

\section{Home Internet connection}

These highly educated, middle and higher middle class women started to use the Internet from home for various purposes. Some started to use the Internet from home as early as 2000 , some as late as 2007 . The majority (eleven) of my sixteen respondents began their use between 2000 and 2005. I expected to find more early adopters and more experienced users in Dhaka than in Rajshahi. Internet connectivity had been available in Dhaka since 1996. However, women in Dhaka took at least three years to start using the technology. Internet services became available in Rajshahi in 2000. Therefore I assumed the users in this city to be much less experienced than Dhaka users. Among eight interviewees in Dhaka, four started between 2004 and 2005 , one in 2002, one in 2001, and two in 1999. This indicates that Bangladeshi women as a group, regardless of location, have got on the cyber bandwagon late.
Compared to women in Dhaka, Rajshahi women were quicker to take advantage of the services of the Internet from home. Out of the eight respondents from Rajshahi, two began to use the Internet from home in each of the years 2000, 2002, 2005 and 2007. The reason for such a fast acceptance may be the quick spread of news of advantages posed by the Internet by word of mouth among women. News media might have played a role here as well. Whenever a new technology enters the country, both the electronic media and newspaper industries run news items, editorials, promotions and special editions on topics related to that technology. I suggest that highly educated women reading and hearing about this new communication technology might have played a role in encouraging women in Rajshahi to use Internet services. Also, Rajshahi is a city that lacks entertainment opportunities and thus women here may have seen the Internet as an alternate source of entertainment. As a consequence they took up the Internet rapidly.

In Indonesia, the reason for Internet adoption among women is said to be due to the "perceived ease of use" (Wahid, 2007, p.3). Regarding the reasons behind the decision to get connected to the Internet at home, my interview responses can be categorized into six broad themes: communication, information, professional or school-related reasons, curiosity, its benefits for children, and its usefulness for male family members (father/brother/son/husband). For both professional and non-professional women, being able to communicate easily and inexpensively with family and friends who live abroad is a significant reason. Besides communication, being able to see them through a webcam or being able to send pictures encourages them to get Internet access at Internet home. Professional women want to access the Internet from home so that they can work while look after their children. Thus, the Internet's ability to blend work and family together has encouraged women to become Internet hofrer thersewives and students, easy access to information for school and other purposes is an important quality of the Internet. For some the reason for getting connected at home is curiosity. They note that as they have heard so much about this technology they 
want to see what it is all about. Thus at first, they got connected on an experimental basis, but later decided to continue with it.

Regarding the reason for home Internet access, I find a response from a housewife (Nargis, 50) in Rajshahi worth mentioning. When asked about her reason, she says that she wants to offer her children the services of this medium, which opens the door to the world. She mentions that she does not want her daughters to grow up like her. She believes that the most convenient way to provide them with up-to-date information and to open their mental horizons and knowledge from a safe and secure place is to have an Internet connection at home. Acknowledging the negative effects of the medium as well, she keeps an eye on her children's usage of the Internet. She describes the reasons for adopting the Internet at home:

"My family is my life and I try my best to protect them and provide them the best. I have two daughters who are in their teens. Being girls they face many problems when they go out. When the services of the Internet became available in Rajshahi, we both [her husband and herself] decided to have it at home so that our children can learn about the world. I did not want them to go to various places and use it there due to security reasons. Nowadays you do not know what can happen. I did not want them to grow up like me. I want them to face the world with the necessary skills and knowledge, which the Internet can help them to achieve. I want them to stand shoulder to shoulder with men and to attain the same skills. They should not allow themselves to be dominated. If they are well prepared with necessary knowledge, no one can stop them and I strongly believe that the home Internet can provide them that knowledge".

This response offers an image of a woman who is trying to advance changes and better opportunities for the next generation of women. The respondent declines, however, to share further details on what she means when she says that she does not want her daughters to be like her. On the basis of her response, I surmise that perhaps her position as a housewife is not a free choice, but has possibly been forced upon her. It is also possible that there is discrimination within her family. Her strong in-depth discussion of women's need to have financial independence in order to be empowered and her repeated emphasis on economic power lead me to this conclusion. While interviewing her, I sensed a silent pain coming from the inequality that she seems to have faced in her life. Through her words, it appears that she is trying to break loose from that domination. She considers women's independence and autonomy as very important. This is a concern stated by more than half of the respondents, both professional and non-professional.

Another reason given for having an Internet connection at home is that a male family member needs it for his education or professional purposes. Raima, 35, NGO worker from Dhaka, says:

"It was mainly for my husband. He wanted to take advantage of the opportunities of the Internet. He thought about the convenience of having it at home so he could find universities and apply online. Rather than using it at his work place or at other places, he thought that, if we had the service at home, then we could access it any time and in that way we would be able to concentrate better".

Responses like this can be seen as a sign of gender inequality within the household, that there is the predominant view that men know more about technology than women, and that men have more power in decision-making processes, in this case regarding technologyrelated decisions. The responses reflect the broader gender discrimination that prevails within Bangladeshi families. Men head the majority of families in Bangladesh and control the position of decision-makers. In a majority of Bangladeshi families, men are seen as the main contributors and guardians, while women, on the other hand, are seen as supporting the men. Jahan (1988) explains the situation:

"Gender-inequality is deeply embedded in the structure of the patriarchal society of Bangladesh. Male dominance and female subordination are basic tenets of 
our social structure. All Bangladeshi social institutions permit, even encourage, the demonstration of the unequal power relation between the sexes and try to perpetuate interests of patriarchy" (cited by Jahan, 1994, pp. 4-5).

This situation of gender inequality can also be found concerning the question of who initiates home Internet adoption. Here once again the majority of respondents report that the male family members of the household took the initiative. Shilpi (25, businesswoman, Rajshahi) explains: "My husband was the initiator. It was he who thought about it and decided that it would be a good idea".

It seems that the decision-making process related to technology is still controlled by men within these households. Speaking about her husband, a woman proudly says that he wanted to take advantage of the opportunities provided by the technology, as if she had no right to enjoy the benefits of anything until he approves (Raima, 35, NGO worker, Dhaka). She does not mention whether or not her husband wanted her to benefit from the advantages of the new technology or not. Other women who identified male members as initiators for adopting this medium at home gave similar responses. This created the impression that they take patriarchal structures for granted. One of the respondents seemed to be surprised that I asked that question, implying that only her father has the right to make decisions in the family. She notes: "Who else? Obviously it was my father" (Tani, 18, student, from Rajshahi). Rahman and Kumar (1998) have noted that there is "limited participation of women in technology adoption decisions in Bangladesh" (cited by Dholakia, Dholakia, Kshetri, 2004, p.16). Also my respondents seem to echo this perspective in the case of the Internet. Eleven respondents identify male members of their family as the initiators of home Internet adoption, three made the decision themselves, and in two cases the decision was taken together.

The initiative factor can be looked at from two angles. First, women in Bangladesh take it for granted that only male family members have decision-making power. They accept this situation as given. Second, there are some Bangladeshi women who realize that men are playing the dominant role in every sector and they have a strong urge within themselves to change this situation. Thus there seem to be two types of Bangladeshi women's attitudes toward patriarchy: those who silently accept patriarchal domination and those who find it problematic and want to voice their feelings.

The data reveal yet another aspect of the issue. Although statistically insignificant, each case carries its own value and thus is worth mentioning. Some women proudly state that they took the initiative for Internet home adoption. Mainly business and professional women fall into this category. Only one housewife notes that she took the initiative. One may argue that these women have financial independence that enables them to make such decisions. This is surely true, but nonetheless such women still may also have to overcome hostility from other family members. In my sample, however, no such respondent reports such hostility. In addition to financial independence, these women may have the freedom within their families to make decisions. It may be the case that not only women, but also some men are trying to bring about positive changes and question patriarchal dominance.

Some male family members encourage their daughters, wives or mothers to the Internet. Some adopted the Internet at home so that the women in the families could learn and take advantage of what is offered by the medium. Sayma (42, housewife, Dhaka) describes with great excitement how her husband "forced" her to learn to use the Internet: "My husband made sure that when we adopt the Internet at home, I must know how to use it. He literally forced me to use it. After work he would come home and make me use the Internet." Similar is the case of Zeenat (20, student, Rajshahi). She says: "My father made sure that his daughters knew about the Internet, I mean knew how to use it and derive the benefits from it so that we would be prepared to compete with others in the job market."

There are also initiatives by women to advance home Internet use. A businesswoman highlighted how she first got access at home before she opened her own business. She explains: 
"At first, I started using the Internet at a cyber café but the bill always came to a large amount, varying each time I used it, and the environment there was not women-friendly. That is the reason for adopting the Internet at home. I used a connection from a nearby cyber café during the hours it was closed. From late evening to early morning I was allowed to use the line by only paying a minimum rate, about 7US\$ per month and there were no installation costs and other fees. This plan really worked out well for me until I had my own business when I needed to have access beyond those certain hours" (Ritu, 24, businesswoman, Rajshahi).

Stories such as these are an indication that some Bangladeshi women are stepping out of their comfort zone and take advantage of the opportunities available. This woman has shown that despite financial and cultural difficulties, she manages to access the Internet. A strong motivation reinforced her creative way of accessing the medium at the cyber café and finally adopting it at home. This may suggest that some of the obstacles may be possible to overcome, if the woman has sufficient motivation and decision-making power and the necessary infrastructure to support her decision.

Internet Service Providers (ISPs) also help by providing various schemes that offer differential rates for peak hours, off-peak hours and early morning hours. Therefore, depending on their financial conditions, subscribers can select different rates. ISPs also offer card systems. Customers can buy cards for certain amounts and spend the hours that are available for these amounts on the Internet. The price of these cards ranges from less than one to fifteen US\$. Based on the need and the context of specific countries, ISPs have formulated their own plans of how to provide Internet access for the population. Now mobile phone companies in Bangladesh are offering wireless services on mobile phones, but the charges are extremely high and not affordable for average Internet users in the country. The majority of my respondents report that their monthly Internet bill is between three to twelve US\$. Compared to the income of the majority of the people in Bangladesh (daily income being 2 US\$ to 3 US $\$$ per day) this is high. Not surprisingly, the data show that middle- and higher-middle-class women are using this technology. Although a respectable amount of Bangladeshi women are using the Internet from home, problems persist, as my respondents note. Infrastructural problems such as the lack of electricity, slow connection speed, and high cost are identified by all as problems associated with accessing the Internet. I believe that in a developing country such impediments are ever present. Language is not mentioned by my respondents as a problem. This may be due to the educational levels of my respondents. Recently the Internet Service Providers Association of Bangladesh has decided to reduce "the access charge for home users" by 25 percent (Hasan, 2008). This may encourage more women to access the Internet from home and, therefore, future studies may show some different patterns.

\section{Conclusion}

Internet facilities were available in Bangladesh much later than in the other developed countries. Due to the existence of gender differentiation in Bangladesh women are facing disadvantages in every aspect of life. It may therefore be assumed that the position of women in Internet use cannot be any different. My study shows that Bangladeshi women are late-adopters of the Internet. But some positive signs of progress have been identified.

It is interesting to see that older women are getting access to the Internet along with the younger ones. Increased educational levels of women help improving the situation of women in Bangladeshi society. The respondents in my survey tended to have a high degree of education. The professional women in the study also had a relatively high income level. As a consequence middle- and upper-middleclass women are accessing the Internet from home to a respectable degree. These homebased Internet users complain about the infrastructural problems and high cost as the main obstacles towards meaningful and constant Internet usage. But these obstacles do 
not stop the women that participated in my study from home Internet usage.

An interesting finding of my study is that women in Rajshahi, a peripheral city, began to use the Internet at home at almost the same time as their counterparts in the capital city Dhaka. The reasons for Internet home adoption varied. Important reasons that were mentioned are the access to information, communication, to satisfy curiosity, or benefits for children and male family members. But my study indicates that the main reason for the adoption of Internet home access in Bangladesh is the satisfaction of demands by male family members. The predominance of this reason confirms the predominance of the patriarchal worldview that men counter to women and therefore have a legitimate right and power in decision-making processes that determine technology adoption in Bangladeshi families. It is primarily the father, husband or son, who is the initiator of Internet home adoption.

But a few business and professional women also have taken the initiative for Internet home access. Their financial independence as well as their rights within the family to take such decisions may have helped them in this endeavor. There are also some male family members, although very few, who are encouraging female household members to use this technology. Besides the patriarchal dominance, these are positive signs and change potentials.

\section{References}

Bakardjieva, M. (2005). Becoming an Internet user in Bulgaria: Notes on a tangled journey. Media Studies/ Studia Medioznawcze, 3(22), 4-15.

Bakardjieva, M. (2005). Internet society: the Internet in everyday life. London: SAGE.

Basic education data and indicators in Bangladesh. (2006). Retrieved April 3, 2008, from http://www.lcgbangladesh.org/Education/reports/Main\%20education\%20data\%20in\%20Bangladesh\%20ver.2.pdf

Cabrera-Balleza, M. (2006). Gender. Retrieved November 7, 2006, from http://www.vecam.org/article565.html.

Chen, W. \& Boase, J. \& Wellman, B. (2002). The Global Villagers: Comparing Internet Users and Uses Around the World. In B. Wellman and C. Haythornthwaite (Ed.), The Internet in Everyday Life (pp.74-113). Oxford: Blackwell.

Choudhury, N. (2004).Women's lives online: Bangladesh perspective. Accepted for presentation at the conference of the 18th International Association of Historians of Asia in Taiwan.

Dholakia, N., Dholakia, R. R. , \& Kshetri, N. (2004). Gender and Internet Usage. In H. Bidgoli (Ed.), The Internet Encyclopedia (pp. 12-22). New York: Wiley.

Global Information Society Watch 2007 Report. (2007). Uruguay: APC and ITeM.

Hafkin , N., \& Taggart, N. (2001). Gender, information technology and developing countries: An analytic study. Retrieved November 6, 2006, from http:// learnlink.aed.org/Publications/Gender_Book/pdf/Exec_Sum.pdf

Harcourt, W. (2002). Women's activism on the net. Gender, Technology and Development, 6(1), 153-157.

Hasan, Md. (2008, June 22). Internet fees for home users drop 25pc. The Daily Star (Dhaka, Bangladesh).

Hynes, D and Rommes, E. (2006). Fitting the Internet into our lives: IT courses for disadvantaged users. In T. Berker, et al. (Eds.), Domestication of media and technology (pp. 125-144). Maidenhead, England: Open University.

Jahan, R. (1994). Hidden danger: Women and family violence in Bangladesh. Dhaka: Women for Women.

Kabeer, N. (2005). Women's labour in the Bangladesh garment industry: Choices and constraints. In H. Moghissi (Ed.), Women and Islam: Critical concepts in sociology (pp. 275-293). New York: Routledge.

Lawley, E. L. (1993). Computers and the Communication of Gender. Retrieved November 6, 2006, from http://www.itcs.com/elawley/gender.html

Liesbet van, Z. (2002). Gendering the Internet: Claims, controversies and cultures. European Journal of Communication, $17(1), 5-23$

Ochieng, R. (2000). The empowerment of women through the Internet: The African women experience. Retrieved November 7, 2006, from http://www.isis.or.ug/docs/2000_internet.pdf

Odame, H.H. (2005). Introduction: Gender and ICTs for development: Setting the context. In M. Valk, et al. (Eds.), Gender and ICTs for development: A global sourcebook (pp. 13-31). Amsterdam: KIT.

Seale, C. (2004). Researching society and culture. London: Sage Publications. 
Silverstone, R. et al., (1992) Information and communication technologies and the moral economy of the household. In R. Silverstone and E. Hirsch (Eds), Consuming technologies: media and information in domestic space (pp. 15-31). London: Routledge.

Statistical Pocket Book 2007, (2008). Retrieved June 21, 2008, from http://www.bbs.gov.bd/dataindex/pb_wb_page.pdf Stromquist, N. (1998). Women in the Third World: An encyclopedia of contemporary Issues. New York: Garland Publishing. Rathgeber, E.M. (2000). Women, men and ICTs in Africa: Why gender is an issue. In E.M. Rathgeber \& E.O. Adera (Eds.), Gender and the information revolution in Africa (pp. 17-34). Ottawa: IDRC.

Richardson, D. (1998, June). The Internet and rural development. The Journal of Development Communication, 9(1), 54-60. UNDP Human Development Report (2007). Fighting climate change: Human solidarity in a divided world. New York: UNDP.

Wahid, F. (2007). Using the technology adoption model to analyze Internet adoption and use among men and women in Indonesia. The Electronic Journal on Information Systems in Developing Countries, 32(6), 1-8.

Wajcman, J. (2000). Reflections on gender and technology studies: In what state is the art? Social Studies of Science 30(3), 447-464.

Youngs, G. (2005). Ethics of access: Globalization, feminism and information society. Journal of Global Ethics, 1(1), 69-84.

\section{About the Author}

Naziat Choudhury obtained an MA degree from the University of Calgary, Canada. Currently she is teaching mass communication and journalism in Bangladesh. Her research interest areas are cyber-activism, online social networking, online relationships, and Internet use in developing countries. 